\title{
Manfaat Jenjang Karir Bagi Staf Perawat Dan Rumah Sakit
}

\author{
Amiruddin $^{1}$, Rr. Tutik Sri Hariyati ${ }^{2}$, Hanny Handiyani ${ }^{2}$ \\ 1. Prodi Keperawatan Belitung Poltekkes Kemenkes Pangkalpinang \\ 2. Departemen Keperawatan Dasar, Fakultas Ilmu Keperawatan Universitas Indonesia. \\ *Email Korespondensi: amir_alsyifa@yahoo.com
}

\begin{abstract}
Abstrak
Tinjauan literatur ini bertujuan untuk mengidentifikasi manfaat jenjang karir bagi staf perawat dan rumah sakit .Metode literature review ini menggunakan tinjauan literatur dengan cara mengidentifikasi 25 artikel jenjang karir perawat yang dipublikasikan antara tahun 1997 sampai dengan tahun 2015. Strategi pencarian menggunakan key words Clinical bladder dan career bladder.Literatur yang digunakan meliputi artikel, dan jurnal Indonesia dan internasional yang berasal dari JKI, proquest, ebscohost, dan scopus.

Hasil evidence base terkait jenjang karir menggambarkan manfaat utama bagi staf perawat menerapkan jenjang karir, meningkatkan pengembangan profesional, meningkatkan kinerja, meningkatkan kepuasan kerja, menumbuhkan budaya kerja dan dan pengakuan. Manfaat bagi rumah sakit, meningkatkan kualitas pelayanan, rekruitmen dan retensi perawat, menghemat biaya dan menurunkan angka turnover.

Program jenjang klinis memberikan manfaat besar bagi staf perawat dan rumah sakit bila didukung penuh oleh pimpinan rumah sakit dan manajer keperawatan, antusiasme perawat, dan komite keperawatan yang saling sinergis dan mampu bekerja sama.
\end{abstract}

Kata kunci: Jenjang karir, staf perawat, rumah sakit

\begin{abstract}
This literature review aims to identify the benefits of career paths for nursing staff and hospitals. This research method uses a literature review by identifying 25 articles of nurses' career levels published between 1997 and 2015. The search strategy uses key words Clinical bladder and career bladder. The literature used includes articles, and Indonesian and international journals originating from JKI, Proquest, ebscohost, and Scopus. Evidence-based results related to career paths illustrate the main benefits for nursing staff implementing career paths, enhancing professional development, enhancing performance, increasing job satisfaction, fostering work culture and recognition. Benefits for hospitals, improving service quality, nurse recruitment and retention, saving costs and reducing turnover rates. The clinical level program provides great benefits for nursing and hospital staff if it is fully supported by hospital leaders and nursing managers, nurse enthusiasm, and nursing committees that are synergistic and able to work together.
\end{abstract}

Keywords: Career path, nursing staff, hospital 


\section{PENDAHULUAN}

Staf perawat di rumah sakit berisiko mengalami kejenuhan dan kebuntuan karir akibat tidak memiliki model dalam pengembangan jenjang klinis. Model jenjang karir memberikan kerangka, arah pengembangan dan kejelasan pengembangan jenjang karir, tanpa model, jenjang karir tidak bisa dikembangkan (Lang YC, 2010).

Ketidakjelasan karir menimbulkan ketiadakpuasan kerja dan tingginya angka turnover perawat. Angka turnover di Rumah Sakit Inova Mount Veron Virginia pada tahun 2001 sebelum penerapan jenjang karir sebesar $14,1 \%$ (Vandervort, 2008). Klinik Fiscal Cotton-O'Neil Tahun 2007 tingkat turnover RN sebesar 8,33\% (Tetuan et al, 2015).

Rumah sakit dituntut untuk mampu menghasilkan pelayanan keperawatan yang berkualitas. Peningkatan kualitas pelayanan sinergis dengan upaya peningkatan mutu perawat melalui aturan yang mendukung praktik profesional dan penguatan organisasi rumah sakit yang mampu merekrut dan mempertahankan perawat (Frellick M, 2011). Struktur organisasi perawat dan proses organisasinya mempengaruhi kondisi kerja perawat dan kualitas perawatan yang diberikan (Maenhout B, 2013).

Di Indonesia secara umum akibat keterbatasan menyebabkan pengembangan karir perawat klinik kurang berkembang. Pengembangan jenjang karir perawat masih berfokus pada pengembangan karir secara sruktural, pengembangan karir perawat masih berdasarkan masa kerja, belum sesuai dengan kompetensi yang dibutuhkan pada setiap tingkat pelayanan keperawatan (Azwir, 2010).

Upaya peningkatan kualitas perawat dan pelayanan keperawatan dapat dilakukan melalui penerapan sistem jenjang karir. Sistem jenjang karir mampu mengembangkan standar dan praktik keperawatan, mendorong praktik perawat berbasis bukti, berpikir kritis, mengembangkan pengetahuan, dan menghasilkan praktik berkualitas (BurketTL, 2010).
Penerapan sistem jenjang karir perawat telah terbukti mampu meningkatkan pengembangan profesional, meningkatkan kinerja, meningkatkan kepuasan kerja, menumbuhkan budaya kerja, dan pengakuan. Manfaat didapat rumah sakit dapat meningkatkan kualitas pelayanan, rekruitmen dan retensi perawat, menghemat biaya dan menurunkan angka turnover. Penekanan telaah literatur ini memberikan penilaian sejauh mana manfaat sistem jenjang karir bagi staf perawat dan rumah sakit berbasis bukti pada praktik klinik keperawatan.

\section{METODE}

Literature review ini menggunakan tinjauan literatur untuk menjawab fenomena manfaat jenjang karir bagi staf perawat dan rumah sakit. Kriteria inklusi dari literature ini adalah artikel dan jurnal mengenai jenjang karir dalam Bahasa Indonesia dan Bahasa Inggris antara tahun 1997-2015 dengan kata kunci jenjang karir ditemukan 45 artikel.

Tinjauan pustaka yang dilakukan dua tahapan, yaitu tahap 1 dan 2. Pada tahap 1, dari 45 artikel yang telah diunduh harus dihapus karena beberapa unduhan kurang relevan dengan topik. Jadi, ada 25 artikel yang dipilih untuk dikaji. Tahap 2, yang dipilih artikel untuk dianalisis terutama tentang manfaat jenjang karir. Ulasan spesifik dilakukan lebih dari 15 artikel yang didukung.

Lintas jurnal yang digunakan untuk mengakses literatur seperti Jurnal Keperawatan Indonesia (JKI), Proquest, EBSCOhost, dan Scopus. Proses penelitian yang telah dilakukan sejak mendapatkan sumber sampai membuat laporan selama 6 bulan (Mei -Oktober 2016). 


\title{
HASIL
}

\author{
Hasil pembahasan meliputi manfaat jenjang karir bagi staf perawat dan rumah sakit
}

\section{Tabel 1.Hasil Resume 15 Artikel Jenjang Karir Perawat}

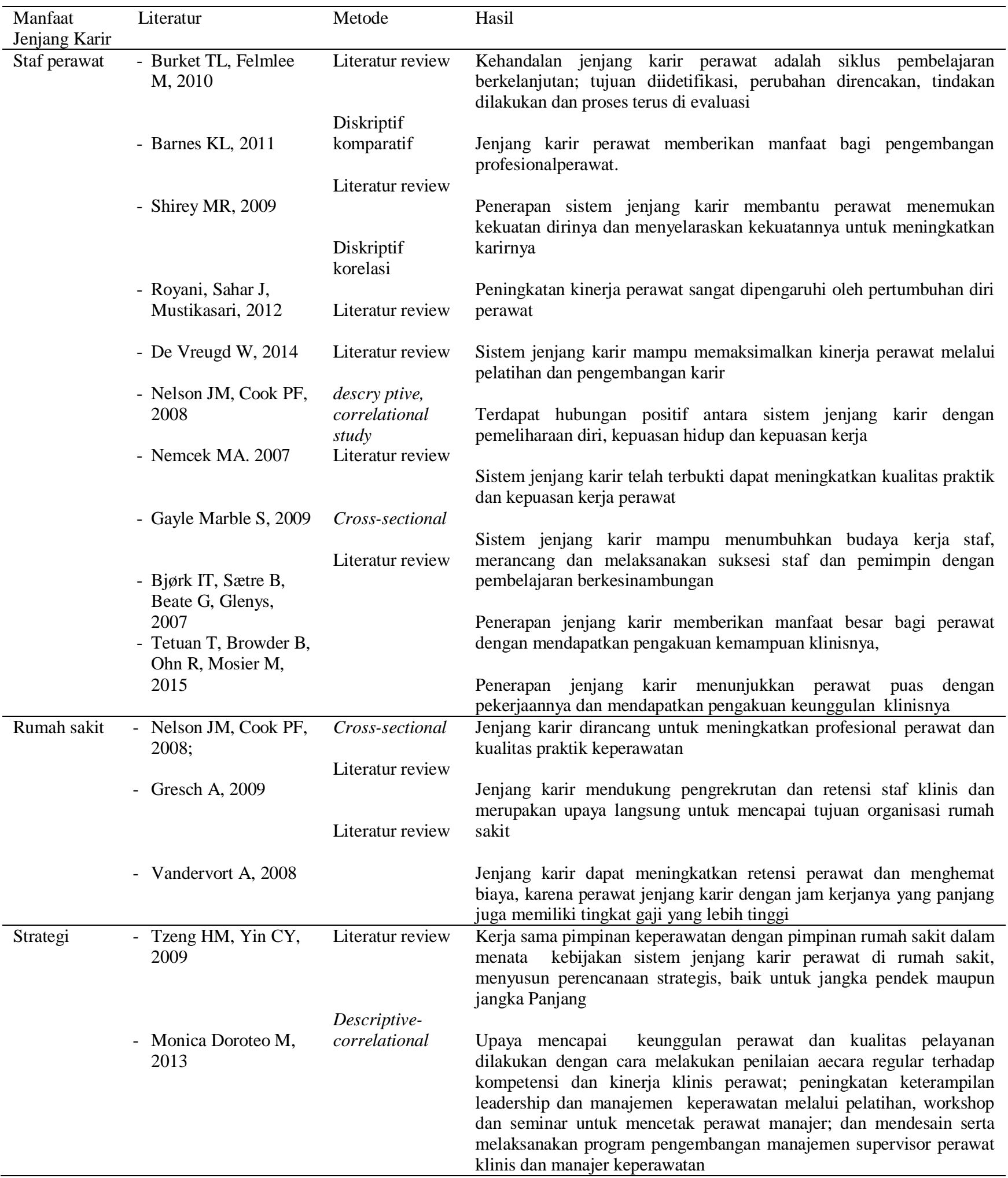




\section{Manfaat jenjang karir bagi staf perawat}

\section{Meningkatkan pengembangan profesional}

Jenjang karir perawat memberikan manfaat bagi pengembangan profesional perawat. Pengembangan profesional dari penerapan sistem jenjang karir di Medical Centre Phonix mampu menghasilkan perawat expert sebanyak $68 \%$ dibanding $18 \%$ sebelum pelaksanaan, perawat bersertifikat $73 \%$ dibanding $24 \%$ sebelum pelaksanaan dan perawat pementor $44 \%$ disbanding 19\% sebelum pelaksanaan (Barnes KL, 2011). Kunci kehandalan sistem jenjang karir perawat adalah siklus pembelajaran berkelanjutan (Burket TL, 2010). Jenjang karir perawat mendorong staf perawat keluar dari zona aman menuju peningkatan karir profesional dan bekerja secara kompeten (Gayle MS, 2009). Perawat klinik memiliki tingkat kepuasan tinggi dalam pengembangan profesional, pengambilan keputusan, tata kelola dan hak otonomi perawat dengan penerapan sistem jenjang karir (Barnes KL, 2011).

\section{Meningkatkan kinerja}

Sistem jenjang karir mampu meningkatkan kinerja perawat. Penerapan sistem jenjang karir membantu perawat menemukan kekuatan dirinya dan menyelaraskan kekuatannya untuk meningkatkan karirnya (Shirey MR, 2009). Peningkatan kinerja perawat sangat dipengaruhi oleh pertumbuhan diri perawat dan menjadi faktor dominan dalam hubungan sistem jenjang karir dengan kinerja perawat (Royani, 2012). Sistem jenjang karir telah mampu memaksimalkan kinerja perawat melalui pelatihan dan pengembangan karir (De Vreugd W, 2014).

\section{Meningkatkan kepuasan kerja}

Sistem jenjang karir perawat mampu meningkatkan kepuasan kerja perawat. Hasil penelitian menunjukkan adanya hubungan positif antara sistem jenjang karir dengan pemeliharaan diri, kepuasan hidup dan kepuasan kerja (Nelson JM, 2008). Sistem jenjang karir telah terbukti dapat meningkatkan kualitas praktik dan kepuasan kerja perawat (Nemcek, 2007).

\section{Menumbuhkan budaya kerja}

Sistem jenjang karir mampu menumbuhkan budaya kerja perawat. Pengembangan sistem jenjang karir perawat memiliki banyak keunggulan dalam berbagai situasi, sistem ini mampu menumbuhkan budaya kerja staf, merancang dan melaksanakan suksesi staf dan pemimpin kunci untuk mengatasi dan mengurangi tantangan strategis dengan pembelajaran berkesinambungan (Gayle MS, 2009). Sistem jenjang karir membudayakan sistem mentor dan kerja tim di masing-masing unit dan mampu menjamin kualitas praktik dan pelayanan keperawatan ke pasien (Burket TL, 2010).

\section{Mendapatkan pengakuan}

Sistem Jenjang karir perawat menumbuhkan pengakuan kemampuan klinis perawat. Penerapan jenjang karir memberikan manfaat besar bagi perawat dengan mendapatkan pengakuan kemampuan klinisnya, pengakuan memberikan dampak meningkatkan kepuasan staf dan menurunkan angka turnover(Bjork, 2007). Penerapan jenjang karir menunjukkan perawat puas dengan pekerjaannya dan mendapatkan pengakuan keunggulan klinisnya (Tetuan T, 2015)

\section{Manfaat jenjang karir bagi Rumah sakit: Meningkatkan kualitas pelayanan dan praktik keperawatan}

Sistem jenjang karir menunjukkan hasil yang positif terhadap kualitas pelayanan dan keselamatan pasien dan merupakan sumbangan terbaik untuk perawatan pasien dan keberhasilan organisasi (Burket TL, 2010). Jenjang karir dirancang untuk meningkatkan profesional perawat dan kualitas praktik keperawatan (Nelson JM, 2008).

\section{Mendukung rekruitmen, retensi perawat dan menghemat biaya}

Jenjang karir dapat meningkatkan retensi perawat dan menghemat biaya, karena perawat jenjang karir dengan jam kerjanya yang panjang juga memiliki tingkat gaji yang 
lebih tinggi, hal ini merupakan faktor retensi yang sangat baik, selain itu dengan membayar gaji yang lebih tinggi secara substansial lebih murah dari pada merekrut atau memperkerjakan perawat pengganti (Vandervort, 2008). Jenjang karir mendukung pengrekrutan dan retensi staf klinis dan merupakan upaya langsung untuk mencapai tujuan organisasi rumah sakit (Gresch A, 2009).

\section{Menurunkan angka turnover}

Penerapan sistem jenjang karir efektif menurunkan angka turnover. Rumah Sakit Bedah di Inova Mount Veron, Virginia meraih kesuksesan dari penerapan sistem jenjang karir perawat setelah sistem ini diterapkan di seluruh sistem kesehatan tahun 2001, angka turnover perawat menurun menjadi 5,2\% dibandingkan $14,1 \%$ sebelum penerapan sistem jenjang karir (Vandervort A, 2008). Rumah Sakit dan Klinik Cotton O'Neil tahun 2007 memiliki tingkat turnoverRegister Nurse sebesar 8,33\% ketika awal program jenjang klinis profesional dilaksanakan. Di Tahun 2012 tingkat turnover 1,96\%, ini menunjukkan pelaksanaan jenjang klinis telah mendukung retensi perawat (Tetuan T, 2015).

\section{Diskusi}

Keterbatasan dari penelitian ini adalah tentang jumlah analisis literatur sehingga ada kemungkinan ditemukan manfaat lain dari penerapan sistem jenjang karir yang lebih luas. Implikasi penelitian ini dapat digunakan sebagai bahan informasi bagi staf perawat dan rumah sakit dalam upaya meningkatkan keuanggulan perawat dan kualitas pelayanan.

Sistem jenjang karir menjadi solusi bagi staf perawat dalam mewujudkan pengembangan karir menjadi perawat profesional yang sebelumnya hanya sebatas harapan dan memberikan manfaat bagi manajer sumber daya manusia rumah sakit dalam menyediakan perawat-perawat unggul untuk mengisi posisi kepemimpinan (Vandervort, 2015). Penerapan sistem jenjang karir memberikan kesempatan bagi staf perawat untuk tumbuh dan merupakan penghargaan pada staf atas leadership, komitmen, inisiatif, kompetensi klinik dan kinerja tinggi yang mereka tunjukkan. Sistem jenjang karir ini memiliki keunggulan karena menghargai kinerja dan prestasi seseorang; memberikan harapan kinerja masa depan; adanya kejelasan uraian tugas, standar kompetensi dan kinerja; memberikan peluang pengembangan karir, mendukung rekrutmen dan retensi staf perawat klinis; upaya nyata untuk mencapai tujuan rumah sakit dan mampu meningkatkan kemampuan staf untuk meraih puncak bakat (Gresch, 2009).

Mencapai manfaat jenjang karir dan penyelesaian masalah sumber daya manusia keperawatan tidak akan mampu diselesaikan di tingkat perawat eksekutif dan perawat klinis. Pimpinan keperawatan harus bekerja sama dengan pimpinan rumah sakit dalam menata kebijakan sistem jenjang karir perawat di rumah sakit. Pimpinan dan manajer keperawatan harus menyusun perencanaan strategis, baik untuk jangka pendek maupun jangka panjang (Tzeng HM, 2009).

Upaya untuk mencapai keunggulan perawat dan kualitas pelayanan dapat dilakukan dengan cara melakukan penilaian regular terhadap kompetensi dan kinerja klinis perawat; peningkatan keterampilan leadership dan manajemen keperawatan melalui pelatihan, workshop dan seminar untuk mencetak perawat manajer; dan mendesain serta melaksanakan program pengembangan manajemen supervisor perawat klinis dan manajer keperawatan (Monica DM, 2013).

\section{SIMPULAN}

Literature review ini menunjukkan banyak manfaat penerapan sistem jenjang karir bagi staf perawat dan rumah sakit. Staf perawat dapat mengembangkan kemampuan profesional, meningkatkan kinerja, kepuasan kerja, menumbuhkan budaya kerja, dan mendapatkan pengakuan, Bagi rumah sakit dengan penerapan sistem jenjang karir mampu memenuhi tuntutan masyarakat dengan menyediakan dan menjamin pelayanan kesehatan yang bekualitas, sistem rektuitmen dan retensi perawat yang baik, 
menghemat biaya dan mampu menurunkan angka turnover. Program jenjang klinis memberikan manfaat besar bagi staf perawat dan rumah sakit bila didukung penuh oleh pimpinan rumah sakit dan manajer keperawatan, antusiasme perawat, dan komite keperawatan yang saling sinergis dan mampu bekerja sama.

\section{SARAN}

Perlunya komitmen bersama antara pimpinan, manajemen keperawatan, perawat dan komite keperawatan suatu RS dalam penerapan system jenjang karir perawat klinik dengan disertai evaluasi dan perbaikan terus menerus dalam upaya mempertahankan dan meningkatkan kinerja perawat dalam memberikan asuhan keperawatan yang berkualitas dan memuaskan bagi pasien.

\section{UCAPAN TERIMA KASIH}

Ucapan rasa terima kasih penulis sampaikan kepada Ibu Dr. RR. Tutik Sri Hariyati, SKp, MARS dan Ibu Dr. Hanny Handiyani, SKp., M.Kep yang telah memberikan bimbingan dan arahan dalam pembuatan manuskrip literatur review ini dan juga kepada Joko Gunawan, Ph.D sebagai translater serta kepada reviewer dan TIM Pengelola JKP yang telah banyak membantu sehingga manuskrip ini dapat diselesaikan dengan baik.

\section{DAFTAR PUSTAKA}

Adams, D. and Elliott, T. S. J. (2006) "Impact of safety needle devices on occupationally acquired needlestick injuries: a four-year prospective study," Journal of Hospital Infection, 64(1), pp. 50-55. doi: 10.1016/j.jhin.2006.04.012.

Azwir, Ayuningtyas, D. and Riastuti (2010) "Pengembangan pola karir perawat klinik rumah sakit umum daerah tarakan jakarta pusat tahun 2008," jurnal Manajemen Pelayanan Kesehatan, 13(01), pp. 16-22. Available at: http://download.portalgaruda.org/article.php? article $=131558 \& \mathrm{val}=5018 \&$ title $=$ Pengemban gan Pola Karir Perawat Klinik Rumah Sakit Umum Daerah Tarakan Jakarta Pusat Tahun 2008.
Barnes, K. L. (2011) "Clinical ladder program participants and job satisfaction: A comparison (Order No. 1502046). Available from ProQuest Dissertations \& Theses Global. (906824958)." Available at: http://search.proquest.com/docview/90682495 8 ? accountid= 17242 .

Beltagy, K. El et al. (2012) "Impact of infection control educational activities on rates and frequencies of percutaneous injuries (PIs) at a tertiary care hospital in Saudi Arabia," Journal of Infection and Public Health. King Saud Bin Abdulaziz University for Health Sciences, 5(4), pp. 297-303. doi: 10.1016/j.jiph.2012.04.002.

Bjørk, I. T. et al. (2007) "Evaluation of clinical ladder participation in norway," Journal of Nursing Scholarship, 39(1), pp. 88-94. Available at: http://search.proquest.com/docview/23634146 9? accountid=17242.

Burket, T. L. and Felmlee, M. (2010) "Clinical ladder program evolution: Journey from novice to expert to enhancing outcomes," The Journal of Continuing Education in Nursing, 41(8), pp. 369-374. doi: 10.3928/00220124-20100503-07.

Darawad, M. W. and Al-Hussami, M. (2013) "Jordanian nursing students' knowledge of , attitudes towards , and compliance with infection control precautions," Nurse education today. Elsevier Ltd, 33(6), pp. 580583. doi: 10.1016/j.nedt.2012.06.009.

Deisenhammer, S. et al. (2006) "Needlestick injuries during medical training," Journal of Hospital Infection, 63, pp. 263-267. doi: 10.1016/j.jhin.2006.01.019.

Frellick, M. (2011) "A path to nursing excellence," Hospitals and Health Networks, 85(4), pp. 41-44. Available at: http://search.proquest.com/docview/86532808 9? accountid=17242.

Gayle Marble, S. (2009) "Five-step model of 
professional excellence," Journal of Oncology Nursing, 13(3), pp. 310-315. Available at: http://search.proquest.com/docview/22275305 4? accountid=17242.

Gresch, A. (2009) "Developing a career ladder," Biomedical Instrumentation and Technology, 43(6), pp. 448-450. doi: 10.2345/0899-8205-43.6.448.

Hambridge, K. (2011) "Needlestick and sharps injuries in the nursing student population," Nursing Standard, 25(27), pp. $38-45$.

Lang, Y. C. (2010) "A clinical ladder for occupational health nurses," AAOHN Journal, 58(6), pp. 239-244. Available at: doi:http://dx.doi.org/10.3928/0891016220100526-01.

Maenhout, B. and Vanhoucke, M. (2013) "Analyzing the nursing organizational structure and process from a scheduling perspective," Health Care Management Science, 16(3), pp. 177-196. doi: 10.1007/s10729-013-9222-6.

van der Molen, H. F. et al. (2011) "Better effect of the use of a needle safety device in combination with an interactive workshop to prevent needle stick injuries," Safety Science. Elsevier Ltd, 49(8-9), pp. 1180-1186. doi: 10.1016/j.ssci.2011.03.010.

Monica Doroteo, M. (2013) "Management Strategies and Leadership Styles of Selected Hospitals for Effective Clinical Nursing Supervision.," Proceedings of the International Conference on Management, Leadership \& Governance, p. 427. Available at:

http://ezproxy.net.ucf.edu/login?url=http://sea rch.ebscohost.com/login.aspx?direct $=$ true $\& \mathrm{db}$ $=$ edb\&AN=87746763\&site $=$ eds-

live $\&$ scope $=$ site.

Nelson, J. M. and Cook, P. F. (2008) "Evaluation of a career ladder program in an ambulatory care environment," Nursing Economics, 26(6), pp. 353-360. Available at: http://www.scopus.com/inward/record.url?eid $=2-\mathrm{s} 2 \cdot 0-59649118488 \&$ partnerID=tZOtx3y1.

Nemcek, M. A. (2007) 'Registered nurses' self-nurturance and life and career satisfaction," AAOHN Journal: Official Journal of The American Association Of Occupational Health Nurses, 55(8), pp. 305311. Available at: http://search.proquest.com/docview/21939819 7 ? accountid=17242.

Nsubuga, F. M. and Jaakkola, M. S. (2005) "Needle stick injuries among nurses in subSaharan Africa," Tropical Medicine and International Health, 10(8), pp. 773-781. doi: 10.1111/j.1365-3156.2005.01453.x.

Rogers, B. and Goodno, L. (2000) "Evaluation of interventions to prevent needlestick injuries in health care occupations.," American journal of preventive medicine, 18(4 Suppl), pp. 90-98. doi: 10.1016/S0749-3797(00)00145-8.

Royani, Sahar, J. and Mustikasari (2012) "Sistem penghargaan terhadap kinerja perawat melaksanakan asuhan keperawatan," Jurnal Keperawatan Indonesia, 15(2), pp. 129-136. Available at: http://jki.ui.ac.id/index.php/jki/article/view/38 138 .

Shirey, M. R. (2009) "Building an extraordinary career in nursing: promise, momentum, and harvest.," Journal of continuing education in nursing, 40(9), pp. 394-400; quiz 401-402, 432. doi: 10.3928/00220124-20090824-01.

Smith, D. R. et al. (2009) "Organizational climate and its relationship with needlestick and sharps injuries among Japanese nurses," American Journal of Infection Control. Elsevier Ltd, 37(7), pp. 545-550. doi: 10.1016/j.ajic.2008.11.004.

Tetuan, T. et al. (2015) "The evaluation of a professional nurse contribution ladder in an integrated health care system," $A A A C N$ Viewpoint, 35(3), pp. 4-8. Available at: 
http://search.proquest.com/docview/14319451 87 ? accountid $=17242$.

Trim, J. C. and Elliott, T. S. J. (2003) “A review of sharps injuries and preventative strategies," Journal of Hospital Infection, 53(4), pp. 237-242. doi: 10.1053/jhin.2002.1378.

Tzeng, H. M. and Yin, C. Y. (2009) "Historical trends in human resource issues of hospital nursing in the past generation," Nurs Econ, 27(1), pp. 19-25. Available at: http://www.ncbi.nlm.nih.gov/pubmed/193313 09.

Vandervort, A. (2008) "Clinical ladder benefits staff, manager," OR Manager, 24(7), pp. 13-14. Available at: http://search.proquest.com/docview/21308928 2 ? accountid $=17242$.

De Vreugd, W. (2014) "Create a career ladder for your case managers Motivating a patient to battle morbid obesity," Case Management Monthly, 11(6), pp. 10-11. Available at: http://search.proquest.com/docview/15341428 91 ? accountid $=17242$.

Yao, W. et al. (2013) "Occupational safety training and education for needlestick injuries among nursing students in China: Intervention study," Nurse Education Today. Elsevier Ltd, 33(8), pp. 834-837. doi: 10.1016/j.nedt.2012.02.004. 